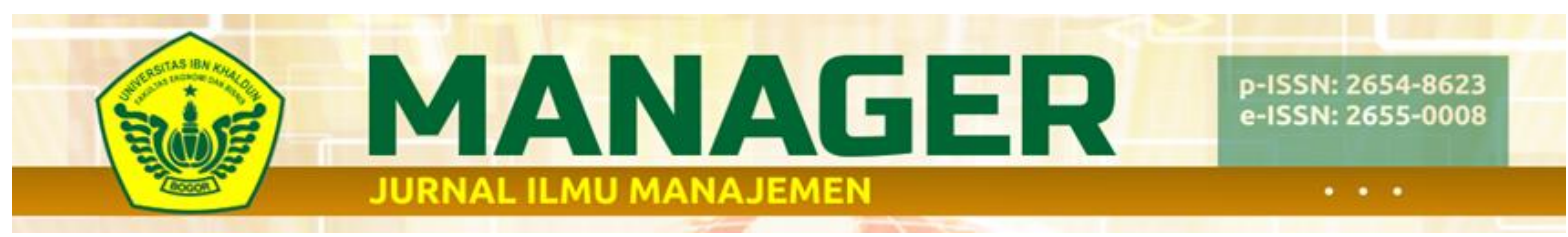

Vol. 2, No. 4, November 2019 Hal 487-493

(c) (1) ()

http://ejournal.uikabogor.ac.id/index.php/Manager/index

\title{
PENGARUH KUALITAS PELAYANAN DAN KEPUASAN PELANGGAN TERHADAP LOYALITAS PELANGGAN
}

\author{
Rosita Nuraeni, Achyar Eldine dan Leny Muniroh \\ Fakultas Ekonomi dan Bisnis Universitas Ibn Khaldun Bogor, Indonesia \\ Nuraenirosita78@gmail.com, Achyar@uika-bogor.ac.id, Lenymuniroh@uika- \\ bogor.ac.id
}

\begin{abstract}
Business in Indonesia is currently growing very rapidly, one of which is the retail business through both offline and online stores, competition is so tight that Hypermart must pay attention to customer loyalty, because customer loyalty is the main goal of the company to develop its business. Customer loyalty is closely related to the quality of service and satisfaction experienced by customers. This research was conducted to find out and get a picture of the extent of the relationship between service quality and customer satisfaction on customer loyalty. The method used is library research and field research with a questionnaire, the population is all visitors to the Hypermart Bellanova Country Mall in July 2019 and a sample of 100 respondents was taken using the Slovin formula. The analytical method used is the instrument test (validity and reliability test), the classic assumption test, multiple regression analysis, correlation and determination coefficients and hypothesis testing using SPSS 25. The results of the analysis show that service quality and customer satisfaction variables have a significant and simultaneous significant effect on customer loyalty. The coefficient of determination (adjusted R2) states that the decision to visit the Hypermart Bellanova country Mall is influenced by two variables of $46.2 \%$ while the remaining $53.8 \%$ is influenced by other factors or variables not included in this study.
\end{abstract}

Keywords: Service Quality; Customer Satisfaction; Customer Loyalty.

\begin{abstract}
Abstrak
Bisnis di Indonesia saat ini telah berkembang sangat pesat, salah satunya adalah bisnis ritel baik lewat toko offline maupun online, Persaingan yang begitu ketat membuat Hypermart harus memperhatikan Loyalitas pelaggan, karena loyalitas pelanggan adalah tujuan utama para perusahaan untuk mengembangkan bisnisnya. Loyalitas pelanggan berkaitan erat terhadap kualitas pelayanan dan kepuasan yang dialami oleh pelanggan. Penelitian ini dilakukan untuk mengetahui dan mendapatkan suatu gambaran sejauh mana hubungan antara kualitas pelayanan dan kepuasan pelanggan terhadap loyalitas pelanggan. Metode yang digunakan adalah riset kepustakaan dan penelitian lapangan dengan alat kuesioner, Populasinya adalah seluruh pengunjung Hypermart Bellanova Country Mall pada bulan Juli 2019 dan diambil sampel sebanyak 100 responden dengan menggunakan rumus slovin. Metode analisis yang digunakan adalah uji instrumen (uji validitas dan uji reliabilitas), uji asumsi klasik, analisis regresi berganda, koefisien korelasi dan determinasi serta pengujian
\end{abstract}


hipotesis menggunakan SPSS 25. Hasil analisis menunjukan variabel kualitas pelayanan dan kepuasan pelanggan berpengaruh signifikan secara simultan dan parsial terhadap loyalitas pelanggan. Koefisien determinasi (adjusted R2) menyatakan bahwa keputusan berkunjung pada Hypermart Bellanova country Mall dipengaruhi oleh dua variabel sebesar 46,2\% sedangkan sisanya 53,8\% dipengaruhi oleh faktor lain atau variabel yang tidak dimasukkan dalam penelitian ini.

Kata kunci : Kualitas Pelayanan; Kepuasan Pelanggan; Loyalitas Pelanggan.

\section{Pendahuluan}

Bisnis di Indonesia saat ini telah berkembang sangat pesat, salah satunya adalah bisnis ritel baik lewat toko offline maupun online, hal tersebut dilihat dari banyak berkembangnya bisnis ritel yang baru di Indonesia. Sehingga memunculkan persaingan antar pebisnis ritel, baik itu dilihat dari segi produk, jenis toko yang semakin beragam atau kualitas pelayanan yang diinginkan oleh konsumen.

Hypermart menjadi salah satu perusahaan ritel terbesar yang mendominasi industri bisnis ritel di Indonesia. Barang-barang paling banyak terdapat di pulau Jawa dan sebagian pulau Sumatera, cabang yang tersebar di hampir seluruh wilayah Jabodetabek dan seluruh kota-kota besar di Indonesia. Hypermart memiliki tempat perbelanjaan yang sangat besar dan luas, untuk memenuhi kebutuhan pelanggan hypermart tidak hanya menjual berbagai macam bahan makanan tetapi juga menyediakan berbagai macam barangbarang rumah tangga, barang-barang elektronik, dan barang-barang kebutuhan sehari-hari.

Persaingan yang begitu ketat membuat Hypermart harus memperhatikan Loyalitas pelaggan. Karena loyalitas pelanggan adalah tujuan utama para perusahaan untuk mengembangkan bisnisnya. Pelanggan yang loyal pada perusahaan akan memberikan prioritas utama dalam memilih produk barang atau jasa. Loyalitas pelanggan juga merupakan sikap positif terhadap perusahaan, komitmen yang mempunyai niat untuk meneruskan pembelian dimasa datang, hal ini dapat berlangsung dalam jangka panjang dan berakhir pada saat terjadi ketidakcocokan yang akan memutus ikatan kuat antara pelanggan dan perusahaan. Loyalitas pelanggan berkaitan erat terhadap kepuasan pelanggan dan kualitas pelayanan yang dialami oleh pelanggan.

Kepuasan pelanggan merupakan tujuan dari suatu bisnis, terciptanya kepuasan pelanggan dapat memberikan beberapa manfaat bagi perusahaan antara lain pengaruh antara perusahaan dan pelanggan menjadi harmonis, memberikan dasar yang baik bagi pembelian ulang dan terciptanya loyalitas pelanggan, dan membentuk suatu rekomendasi dari mulut ke mulut yang menguntungkan untuk perusahaan.

Kualitas pelayanan adalah salah satu cara untuk menarik perhatian pelanggan agar pelanggan dapat loyal terhadap perusahaan, selain itu perusahaan harus bisa memahami apa yang menjadi keinginan dan kebutuhan pelanggan, dengan memahami hal tersebut maka akan memberikan saran yang penting bagi perusahaan untuk melakukan strategi pemasaran yang baik 
serta akan meningkatkan volume penjualan bagi perusahaan tersebut.

\section{Identifikasi Masalah}

Dalam penelitian ini penulis mengidentifikasi masalah sebagai berikut:

1. Bagaimana pengaruh kualitas pelayanan terhadap loyalitas pelanggan pada Hypermart Bellanova Country Mall.

2. Bagaimana pengaruh kepuasan pelanggan terhadap loyalitas pelanggan pada Hypermart Bellanova Country Mall.

3. Bagaimana pengaruh kualitas pelayanan dan kepuasan pelanggan terhadap loyalitas pelanggan pada Hypermart Bellanova Country Mall.

\section{Tujuan Penelitian}

Adapun tujuan melakukan penelitian ini adalah sebagai berikut :

1. Untuk Mengetahui pengaruh kualitas pelayanan terhadap loyalitas pelanggan pada Hypermart Bellanova Country Mall.

2. Untuk mengetahui pengaruh pengaruh kepuasan pelanggan terhadap loyalitas pelanggan pada Hypermart Bellanova Country Mall.

3. Untuk mengetahui pengaruh kualitas pelayanan dan kepuasan pelanggan terhadap loyalitas pelanggan pada Hypermart Bellanova Country Mall.

\section{Metode Penelitian}

\section{Teknik Pengumpulan Data}

Pengumpulan data penelitian dimaksud sebagai peencatatan peristiwa atau karakteristik dari sebagian atau sebagian atau seluruh elemen populasi penelitian. Pengumpulan data penelitian dapat dilakukan berdasarkan cara-cara tertentu. Berdasarkan pengumpulannya, yang digunakan peneliti adalah sebagai berikut :

1. Studi pustaka

Suatu pengumpulan data dengan jelas mengumpulkan literature-literature, tulisan ilmiah, serta sumber tertulis utama diperpustakaan seperti buku yang berhubungan dengan objek penelitian.

2. Penelitian lapangan

1. Observasi.

2. Wawancara.

3. Kuesioner.

\section{Populasi}

Populasi dalam penelitian ini adalah 25.000 pengunjung Hypermart dalam waktu 1 bulan.

\section{Prosedur Penarikan Sampel}

Dalam usaha pengambilan sampel yang harus diambil, penulis menggunakan metode slovin untuk menentukan berapa besar minimal sampel yang dibutuhkan jika ukuran populasi sudah diketahui. Rumus slovin adalah :

$$
\begin{aligned}
& n=\frac{N}{1+N \cdot e^{2}} \\
& n=\frac{25000}{1+25000.10 \%^{2}} \\
& n=\frac{25000}{1+25000.0,1^{2}} \\
& n=\frac{25000}{251} \\
& n=99,60 \infty 100
\end{aligned}
$$


keterangan:

$\mathrm{N}=$ jumlah populasi

$\mathrm{n}=$ jumlah sampel

$\mathrm{e}=$ nilai presisi (tingkat kepercayaan

$90 \%$ maka e $=10 \%$ )

\section{Hasil dan Pembahasan}

Berdasarkan hasil kuesioner yang disebarkan kepada 100 orang responden, diperoleh hasil 27 orang responden berjenis kelamin pria dan sisanya perempuan. Mayoritas responden umum ( ibu rumah tangga, pegawai, pengusaha dan lain-lain ) dengan usia lebih dari (>) 25 tahun.

Dapat diketahui bahwa untuk variabel kualitas pelayanan dengan 9 pertanyaan yang ada dalam instrumen penelitian dinyatakan valid, semua butir pertanyaan memiliki nilai $\mathrm{r}$ hitung $>\mathrm{r}$ tabel dengan $r$ tabel $(\mathrm{N}=100)=0,195$, nilai korelasi terbesar ada pada pertanyaan X2.5 dengan nilai $r=0,751$.

Dapat diketahui bahwa untuk variabel kepuasan pelanggan dengan 7 pertanyaan yang ada dalam instrumen penelitian dinyatakan valid, semua butir pertanyaan memiliki nilai $\mathrm{r}$ hitung $>\mathrm{r}$ tabel dengan $r$ tabel $(\mathrm{N}=100)=0,195$, nilai korelasi terbesar ada pada pertanyaan Y6 dengan nilai $r=0,769$.

Dapat diketahui bahwa untuk variabel loyalitas pelanggan dengan 7 pertanyaan yang ada dalam instrumen penelitian dinyatakan valid, semua butir pertanyaan memiliki nilai $r$ hitung $>r$ tabel dengan $r$ tabel $(\mathrm{N}=100)=0,195$, nilai korelasi terbesar ada pada pertanyaan X1.1 dengan nilai $r=0,778$.

Hasil pengujian reliabilitas kualitas pelayanan dengan nilai koefisien alpha
0,765 maka disimpulkan bahwa hasil pengujian tersebut reliabel, artinya pertanyaan yang ada dapat digunakan karena memiliki nilai Cronbach's Alpha diatas 0,6 .

Hasil pengujian reliabilitas kepuasan pelanggan dengan nilai koefisien alpha 0,787 maka disimpulkan bahwa hasil pengujian tersebut reliabel, artinya pertanyaan yang ada dapat digunakan karena memiliki nilai Cronbach's Alpha diatas 0,6 .

Hasil pengujian reliabilitas loyalitas pelanggan dengan nilai koefisien alpha 0,798 maka disimpulkan bahwa hasil pengujian tersebut reliabel, artinya pertanyaan yang ada dapat digunakan karena memiliki nilai Cronbach's Alpha diatas 0,6 .

\section{Uji t (Parsial)}

t hitung untuk variabel kualitas pelayanan sebesar 0,484 dengan tingkat signifikansi $0,630, \mathrm{t}$ hitung untuk variabel kepuasan pelanggan sebesar 4,874 dengan tingkat signifikansi 0,000.

Hasil uji f variabel X1 (kualitas pelayanan) dan X2 (kepuasan pelanggan) diperoleh nilai $\mathrm{f}$ hitung $=$ 41,627 dengan tingkat signifikansi 0,000 . Dengan menggunakan batas signifikansi 0,05 , terlihat hasil penelitian menunjukan angka sig $<0,05$ berarti bahwa semua variabel bebas yaitu variabel X1 (kualitas pelayanan) dan X2 (kepuasan pelanggan) secara bersamasama memiliki pengaruh positif yang signifikan terhadap variabel terikat yaitu loyalitas pelanggan. Dengan demikian Ho ditolak, Ha diterima.

Model persamaan regresi yang dapat dituliskan dari hasil tersebut dalam 
bentuk persamaan regresi standardized adalah sebagai berikut :

$$
\mathrm{Y}=7,011+0,052 \mathrm{X} 1+0,616 \mathrm{X} 2
$$

Persamaan regresi yang dapat dituliskan dari hasil tersebut dijelaskan sebagai berikut : Dari persamaan tersebut dapat terlihat bahwa keseluruhan variabel bebas (kualitas pelayanan, dan kepuasan pelanggan) berpengaruh positif terhadap minat beli ulang konsumen. Berdasarkan persamaan dapat diketahui bahwa variabel bebas yang berpengaruh adalah kualitas pelayanan dengan koefisien 0,052 (ketika nilai variabel bebas $\mathrm{X} 2=$ 0 ), seangkan variabel yang berpengaruh paling tinggi yaitu variabel kepuasaan pelanggan dengan nilai koefisien 0,616 (ketika nilai vaariabel bebas $\mathrm{X} 1=0$ ).

Dari hasil perhitungan dengan menggunakan program SPSS versi 25.0 dapat diketahui bahwa koefisien determinasi atau $\mathrm{R}$ Square adalah sebesar 0,462. Nilai $R$ Square 0,462 ini berasal dari pengkuadratan nilai koefisien korelasi atau $\mathrm{R}$ yaitu $0,680 \mathrm{x}$ $0,680=0,462$. Besarnya angka koefisien determinasi ( $\mathrm{R}$ Square) adalah 0,462 atau sama dengan 46,2\%. Angka tersebut mengandung arti bahwa variabel kualitas pelayanan (X1) dan kepuasan pelanggan (X2) secara simultan (bersama-sama) berpengaruh terhadap variabel loyalitas pelanggan(Y) sebesar $46,2 \%$. Sedangkan sisanya $53,8 \%$ dipengaruhi oleh variabel lain diluar persamaan regresi ini atau variabel yang tidak diteliti.

\section{III.Kesimpulan Dan Saran}

\section{Kesimpulan}

Kesimpulan dari hasil pembahasan tentang pengaruh kualitas pelayanan dan kepuasan pelanggan terhadap loyalitas pelanggan pada Hypermart Bellanova Country Mall adalah sebagai berikut :

1. Kualitas pelayanan memiliki pengaruh terhadap loyalitas pelanggan pada Hypermart Bellanova Country Mall. Hal tersebut dibuktikan dengan hasil penelitian yang diuji dengan SPSS :

Hasil uji t untuk variabel X1 (kualitas pelayanan) diperoleh nilai $\mathrm{t}$ hitung sebesar 0,484 dengan tingkat signifikansi 0,630. Dengan menggunakan batas signifikansi uji 0,05. Variabel kualitas pelayanan memiliki tingkat signifikansi 0,630, karena tingkat signifikansi lebih dari $5 \%(0,630<0,05)$ atau thitung $0,484<\mathrm{t}$ tabel 1,660, maka disimpulkan bahwa kualitas pelayanan berpengaruh positif tetapi tidak signifikan terhadap variabel loyalitas pelanggan. Dengan kata lain dapat disimpulkan bahwa suatu kualitas pelayanan mempengaruhi loyalitas pelanggan.

Analisi regresi linier berganda : Model persamaan regresi yang dapat dituliskan dari hasil tersebut dalam bentuk persamaan regresi standardized adalah $\mathrm{Y}$ $=7,011+0,052 \mathrm{X} 1+0,616 \mathrm{X} 2$ dari persamaan regresi tersebut dapat diketahui ketika nilai variabel $\mathrm{X} 2$ (kepuasan pelanggan) memiliki nilai $=0$ maka variabel X1 (Kualitas Pelayanan) memiliki nilai Koefisien 0,052 atau $05.2 \%$ berpengaruh terhadap variabel $\mathrm{Y}$ (loyalitas pelanggan).

2. Kepuasan pelanggan memiliki pengaruh terhadap loyalitas pelanggan pada Hypermart Bellanova Country Mall. Hal tersebut dibuktikan dengan hasil penelitian yang diuji dengan SPSS : 
Hasil uji t untuk variabel X1 (kualitas pelayanan) diperoleh nilai $\mathrm{t}$ hitung sebesar 4,874 dengan tingkat signifikansi $\quad 0,000 . \quad$ Dengan menggunakan batas signifikansi uji 0,05. Variabel kepuasan pelanggan memiliki tingkat signifikansi 0,000, karena tingkat signifikansi kurang dari 5\% $(0,000<0,05)$ atau $t$ hitung 4.874 , maka disimpulkan bahwa kepuasan pelanggan berpengaruh positif dan signifikan terhadap variabel loyalitas pelanggan. Dengan kata lain dapat disimpulkan bahwa suatu kepuasan pelanggan akan mempengaruhi loyalitas pelanggan.

Analisi regresi linier berganda : Model persamaan regresi yang dapat dituliskan dari hasil tersebut dalam bentuk persamaan regresi standardized adalah Y $=7,011+0,052 \mathrm{X} 1+0,616 \mathrm{X} 2$ dari persamaan regresi tersebut dapat diketahui ketika nilai variabel X1 (kualitas pelayanan) memiliki nilai $=0$ maka variabel X2 (Kepuasan pelanggan) memiliki nilai Koefisien 0,616 atau $61.6 \%$ berpengaruh terhadap variabel $\mathrm{Y}$ (loyalitas pelanggan).

3. Kualitas pelayanan dan kepuasan pelanggan bersama-sama memiliki pengaruh terhadap loyalitas pelanggan pada Hypermart Bellanova Country Mall. Hal tersebut dibuktikan dengan hasil penelitian yang diuji dengan SPSS :

Uji Validitas : Hasil Uji Validitas menunjukan $\mathrm{N}=100$ dengan persentase validitas $100 \%$ valid

Uji Reliabilitas : Hasil Uji didapatkan nilai koefisien alpha sebesar 0,765 untuk variabel $\mathrm{X} 1,0,787$ untuk variabel $\mathrm{X}$ 2, dan 0,798 untuk variavel $\mathrm{Y}$, artinya menunjukan kuesioner untuk variabel $\mathrm{X} 1, \mathrm{X} 2$ dan Y cukup handal.
Uji f : Hasil Uji f kedua Variabel X1 (Kualitas Pelayanan) dan X2 (Kepuasan Pelanggan) diperoleh nilai $\mathrm{f}$ hitung $=$ 41,627 dengan tingkat signifikan $=0,000$ (batas signifikan $=0,05)$ tingkat signifikan < batas signifikan $(0,000<$ $0,05)$, ini berarti bahwa kedua variabel memiliki pengaruh yang signifikan terhadap variabel Y (Kulaitas Pelayanan).

Koefisien Determinasi : Hasil Uji Koefisien Determinasi didapatkan nilai koefisien determinasi variabel X1 dan $\mathrm{X} 2$ secara serempak mempunyai nilai $=$ 0,462, ini berarti variabel $\mathrm{X} 1$ dan $\mathrm{X} 2$ secara serempak berpengaruh sebesar 46,2\% terhadap Variabel Y, sedangkan sisanya yaitu $53,8 \%$ dipengaruhi oleh variabel-variabel lain.

\section{Saran}

Saran yang dapat diberikan atas hasil dan pembahasan dari kesimpulan mengenai pengaruh kualitas pelayanan dan kepuasan pelanggan terhadap loyalitas pelanggan pada Hypermart Bellanova Country Mall adalah sebagai berikut :

1. Dari hasil rekapitulasi nilai variabel kualitas pelayanan diketahui terdapat nilai persepsi pelanggan yang paling rendah yaitu dengan jumlah rata-rata 3,61 dengan butir pernyataan : Hypermart Bellanova Country Mall memberikan informasi yang cepat, menarik dan baik kepada pelanggan, dari hal-hal demikian dapat disarankan kepada Hypermart Bellanova Country Mall untuk memperbaiki pelayanan informasi agar lebih baik dan menarik lagi dalam memberikan informasi sehingga pelanggan menjadi loyal kepada perusahaan. 
2. Dari hasil rekapitulasi nilai variabel kepuasan pelanggan diketahui terdapat nilai persepsi pelanggan yang paling rendah yaitu dengan jumlah rata-rata 3,44 dengan butir pernyataan : pelayanan yang diberikan Hypermart Bellanova Country Mall melebihi harapan saya, dari hal-hal demikian dapat disarankan kepada Hypermart Bellanova Country Mall untuk meningkatkan pelayanan agar bisa menumbuhkan kepuasan yang dirasakan sesuai dengan harapan dan ekspetasi pelanggan.

\section{Daftar Pustaka}

Hurriyati, Ratih. Bauran Pemasaran dan Loyalitas Konsumen. Bandung: Alfabeta, 2015.

Lovelock, Christopher, Jochen Writz, dan Jacky Mussry. Pemasaran Jasa Manusia, Teknologi, Strategi. 7 ed. Erlangga, 2010.

Sunyoto, Danang. Konsep Dasar Riset Pemasaran dan Perilaku Konsumen. Yogyakarta: CAPS (Center of Academc Publishing Service, 2018.

Fiqihta, Elmi, Ecin Kuraesin, dan Leny Muniroh. "Kualitas Pelayanan Dan Brand Image Terhadap Kepuasan Pelanggan." Manager: Jurnal Ilmu Manajemen 2, no. 1 (2019): 127-44.

Mutia, Achyar Eldine, dan Leny Muniroh. "Kualitas Pelayanan Dan Pemuasan Pelanggan Terhadap Loyalitas Pelanggan." Manager: Jurnal Ilmu Manajemen 1, no. 1 (1 November 2018): 5773. 